\title{
Association between Medication Adherence and Duration of Outpatient Treatment in Patients with Schizophrenia
}

\author{
Seiichiro Tarutani ${ }^{1,2} \bowtie$, Hiroki Kikuyama ${ }^{1,2}$, Munehiro Ohta ${ }^{1}$, Tetsufumi Kanazawa ${ }^{1,2}$, \\ Takehiko Okamura1, and Hiroshi Yoneda ${ }^{1,2}$ \\ 1'Department of Psychiatry, Shin-Abuyama Hospital, Osaka Institute of Clinical Psychiatry, Osaka, Japan \\ ${ }^{2}$ Department of Neuropsychiatry, Osaka Medical College, Osaka, Japan
}

Objective Medication adherence is important in the treatment of schizophrenia, and critical periods during treatment may be associated with relapse. However, the relationship between adherence and duration of outpatient treatment (DOT) remains unclear. The authors aimed to clarify the relationship between adherence and DOT at a psychiatric hospital in Japan.

Methods For outpatients with schizophrenia who regularly visit Shin-Abuyama hospital, the authors conducted a single questionnaire survey (five questions covering gender, age, DOT, medication shortages, and residual medication) over one month period. Participants were divided into two groups whether DOT were from more than one year to within five years or not. Mantel-Haenszel analysis and logistic regression analysis were performed on the data regarding the medication adherence.

Results Effective answers were received for 328 patients. The residual medication rate was significantly higher among those receiving outpatient treatment from more than one year to within five years than five years than those receiving outpatient treatment for more than five years or less than one year $(\mathrm{p}=0.016)$.

Conclusion This survey suggests that there are critical periods during which patients are most prone to poor adherence. Because poor adherence increases the risk of relapse, specific measures must be taken to improve adherence during these periods.

Psychiatry Investig 2016;13(4):413-419

Key Words Schizophrenia, Medication adherence, Outpatients, Questionnaires, Critical period.

\section{INTRODUCTION}

Schizophrenia is one of the most famous and serious diseases in psychiatric field. Despite of many efforts which human try to understand the principle with many ways, we haven't get all yet. Only we know that this disease is hard to cure and needs continuous treatment. We psychiatrists know that one of the aims of treatment for patients with schizophrenia is prevention of relapse or readmission.

Relapse in patients with schizophrenia is closely related to

Received: October 25, 2015 Revised: December 28, 2015

Accepted: December 31, 2015 Available online: March 23, 2016

$\triangle$ Correspondence: Seiichiro Tarutani, MD

Department of Psychiatry, Shin-Abuyama Hospital, Osaka Institute of Clinical Psychiatry, 4-10-1, Nasahara, Takatsuki-shi, Osaka 569-1041, Japan

Tel: +81-72-693-1881, Fax: +81-72-693-3029, E-mail: dtarutan@gmail.com Department of Neuropsychiatry, Osaka Medical College, 2-7, Daigakumachi, Takatsuki-shi, Osaka 569-8686, Japan

Tel: +81-72-683-1221, Fax: +81-72-683-4810, E-mail: dtarutan@gmail.com

(a) This is an Open Access article distributed under the terms of the Creative Commons Attribution Non-Commercial License (http://creativecommons.org/licenses/bync/3.0) which permits unrestricted non-commercial use, distribution, and reproduction in any medium, provided the original work is properly cited. medication adherence, ${ }^{1-3}$ which itself has many influences. ${ }^{4,5}$ To date, numerous reports have considered different ways of checking medication adherence, including patient questioning, relative questioning, medication adherence rating, electronic monitoring using MEMS (Medication Event Monitoring System), ${ }^{6-8}$ pill counting, and injection counting. ${ }^{9,10}$

Several disparate factors are relevant to medication adherence. Antipsychotics are clearly effective in the treatment of schizophrenia, ${ }^{11}$ second-generation antipsychotics appear to benefit from superior adherence rates ${ }^{12-16}$ and medication adherence is also dependent on the type and formulation of the medicine used. ${ }^{17,18}$ Additionally, adherence may be poor because many patients with schizophrenia often begin treatment against their will, ${ }^{2,19}$ and may not have had the purpose of their treatment explained to them. ${ }^{20}$ Financial incentives, hope, and a recovery attitude are needed to maintain motivation during treatment. ${ }^{21,22}$ Particularly during involuntary treatment, the law of effect suggests that a favorable outcome would strengthen the action that produced it. ${ }^{23}$ Thus, collaborative management in the sharing of therapeutic targets and under- 
standing patient motivation is key, raising the significance of self-reporting.

As mentioned above, since the treatment of patients with schizophrenia often commences at involuntary admission, intensive outpatient care is needed to prevent a reduction in adherence. ${ }^{24}$ Tiihonen found that the mortality rate among patients with schizophrenia on antipsychotic medication was low in the $0-0.5$ years period (HR 0.35 ). After that period, it worsened particularly in $0.5-2.0$ years and was gradually better until 5.0 years. Further, it became lowest in 5.0-7.0 years (HR 0.73 ). In other words, risk of death became lower in bimodal both in $0-0.5$ years and 5.0-7.0 years. ${ }^{25}$ Moreover, Robinson reported that the risk of relapse was $16.2 \%$ within 1 year, $37.5 \%$ in $1-2$ years, $9.4 \%$ in $2-3$ years, $11.6 \%$ in $3-4$ years and $7.2 \%$ in $4-5$ years. ${ }^{26}$ It showed the same trend as Tiihonen's report; risk of relapse also became in bimodal. It became higher after one year of onset and lower the closer to five years.

Therefore, they suggest that adherence is good within the first year of treatment, but worsens over the subsequent 1-5 years. This is an important hypothesis, which to the best of our knowledge has not yet been addressed in the literature. The present cross-sectional study was therefore performed to clarify whether the reduced adherence observed at 1-5 years after the initiation of the treatment is helpful in the clinical setting. On the basis of these factors, we conducted a single questionnaire survey to identify opinions of outpatients with schizophrenia at our hospital.

\section{METHODS}

To clarify the relationship between medication adherence and the duration of outpatient treatment (DOT) at our hospital, we conducted a cross-sectional study using a single questionnaire survey among outpatients with schizophrenia who regularly attended our hospital.

The relationship between medication adherence and DOT was set as a primary endpoint. A secondary endpoint was identification of the factors influencing adherence, as analyzed using a regression model.

\section{Subjects}

Outpatients with schizophrenia at our hospital who attended regular outpatient appointments were invited to participate in this questionnaire-based survey. The study was conducted for four weeks between January 10 and February 6, 2012, which is the shortest interval typically used by us for outpatient review. Schizophrenia was diagnosed based on code F20 of the International Classification of Diseases, Tenth Revision (ICD-10). ${ }^{27}$ The questionnaire was based on that of the National Federation of Mental Health and Welfare Party in Ja- pan. ${ }^{28}$ We set five questions covering gender, age, DOT at our hospital, medication shortages, and residual medication.

Consecutive patients were recruited after they had seen their doctor, in order to reduce the effect of reporting bias. They were provided with a verbal explanation together with a written brief regarding the design of the study. Consent to participate was then obtained verbally from the patients. The enrolled participants were asked to complete the questionnaire anonymously; the questionnaires were collected immediately upon completion, and consent was assumed at that point. The institutional review board of Shin-Abuyama Hospital, Osaka Institute of Clinical Psychiatry approved the use of this survey. Questionnaires were kept securely and processed so that patient identification was not possible.

\section{Questionnaire variables}

Responses to questions about gender and age were required for effective answers because age may be related to the DOT and gender is a known prognostic factor in schizophrenia.

We set a question with four choices: less than one year $(<1$ year); one year or more to fewer than five years (1-5 years); five years or more to fewer than 10 years (5-10 years); and 10 years or more ( $\geq 10$ years). A multiple-choice question was chosen to stratify the answers and to encourage more accurate reporting by participants.

The terms "medication shortage" and "residual medication" are sometimes used to describe situations in which patients were taking too many or too few medications, respectively. However, since these situations can be affected by many factors in patients with schizophrenia, we defined them as "medication shortage"/"residual medication" from any cause, according to the self-reporting dichotomous response of "yes or no" on the questionnaire.

\section{Analysis of the critical period for adherence}

To analyze the relationship between the DOT and medication shortages or residuals, we formed two categorical data groups based on the DOT: a "core period" group (1-5 years), and an "other" group ( $<1$ year or $\geq 5$ years). Our rationale was that the critical period for medication adherence in patients with schizophrenia occurs between one and five years from diagnosis. ${ }^{26}$ However, because of changes in where patients received treatment, the precise time of onset was not always known and could have resulted in reporting bias. Therefore, we used the DOT at our hospital as a surrogate marker of duration from onset to provide an objective indicator of adherence.

\section{Statistical analysis}

Frequencies and proportions were provided for all categorical data. The mean and standard deviation (SD) or the median 
and range were provided for quantitative data. We applied the Pearson $\chi^{2}$ test to determine the relationship between outpatient treatment duration and the rate of medication shortage or residual medication. Gender was analyzed as a stratification factor by Mantel-Haenszel analysis, which provided odds ratio (OR) for the categorical data, with $95 \%$ confidence intervals $(\mathrm{CI})$. When analyzing the outpatient treatment duration and the medication shortages or residuals, we considered all responses to be effective answers.

In the analysis using a logistic regression model to identify predictors affecting poor adherence, medication shortage or residual medication were adopted as dependent variables, and gender, age, and DOT as independent variables. The patients were stratified into the following age groups: $<30$ years, 30-39 years, $40-49$ years, $50-59$ years, and $\geq 60$ years. Since only three of the patients were younger than 20 years, their data were pooled together with those from the $<30$-years age group.

p-values $<0.05$ were accepted as indicating significance, and all were two-tailed. All statistical analyses were performed using IBM SPSS Statistics version 19 for Mac (Chicago, IL, USA).

\section{RESULTS}

In total, 377 patients with schizophrenia visited our hospital for treatment within the research period, of which 330 agreed to participate. However, effective answers were only received for 328 patients, providing a response rate of $87 \%$. Of these, $65 \%$ (246/377) have continued to visit our hospital since onset. In addition, adding patients who visited our hospital more than five years (i.e., they had already experienced more than five years from onset), $76 \%$ (286/377) of them met classification criteria.

Table 1 summarizes the data for gender, age, DOT, and the medication shortages or residuals in the final sample. The numbers of males and females were comparable but the age of females tended to be significantly higher (Mann Whitney test, $\mathrm{p}<0.001)$. There were 321,319 and 319 effective answers to the questions about outpatient treatment duration, medication shortages, and residual medication, respectively. As demonstrated, 7\% (24/321) had medication shortages, 41\% $(132 / 319)$ had residual medication, and $44 \%(140 / 319)$ had both medication shortages and residuals.

Table 2 shows the results of the $\chi^{2}$ test between the DOT at our hospital and medication shortages (318 effective answers). The core period group (1-5 years) comprised 91 patients, of which 84 had no drug shortages and seven did. The other group ( $<1$ year or $\geq 5$ years) was comprised of $227 \mathrm{pa}$ tients, of which 210 had no drug shortages and $17 \mathrm{did}$. There were no significant differences between the results $\left(X^{2}=0.004\right.$, $\mathrm{df}=1, \mathrm{p}=0.951$ ). And it shows the $\chi^{2}$ test between the DOT
Table 1. Basic participant response $(\mathrm{N}=328)$

\begin{tabular}{|c|c|c|}
\hline Characteristics & $\mathrm{N}$ & $\%$ \\
\hline \multicolumn{3}{|l|}{ Gender } \\
\hline Male & 167 & 51 \\
\hline Female & 161 & 49 \\
\hline \multicolumn{3}{|l|}{ Age $($ mean $\pm S D)$} \\
\hline Male & $45.2 \pm 13.6$ & - \\
\hline Female & $51.5 \pm 15.4$ & - \\
\hline \multicolumn{3}{|c|}{$\begin{array}{l}\text { Duration of outpatient treatment } \\
\text { at Shin-Abuyama Hospital }\end{array}$} \\
\hline$<1$ year & 31 & 9 \\
\hline $1-5$ years & 92 & 28 \\
\hline $5-10$ years & 85 & 26 \\
\hline$\geq 10$ years & 116 & 35 \\
\hline No answer & 4 & 5 \\
\hline \multicolumn{3}{|l|}{ Medication shortages } \\
\hline "Yes" & 24 & 7 \\
\hline "No" & 297 & 91 \\
\hline No answer & 7 & 2 \\
\hline \multicolumn{3}{|l|}{ Residual medications } \\
\hline "Yes" & 132 & 40 \\
\hline "No" & 187 & 57 \\
\hline No answer & 9 & 3 \\
\hline \multicolumn{3}{|c|}{ Medication shortages or residuals } \\
\hline "Yes" & 140 & 43 \\
\hline "No" & 179 & 55 \\
\hline No answer & 9 & 3 \\
\hline
\end{tabular}

The response rate was $87 \%(328 / 377)$ or outpatients that regularly visited Shin-Abuyama Hospital. Effective answers were those questionnaires completed with data for sex and age

and residual medication (316 effective answers). The core period group comprised 91 patients, of which 47 had residual drugs and 44 did not. The other group contained $225 \mathrm{pa}-$ tients, of which 83 had residual drugs, and 142 did not. There was a significant difference between the groups $\left(\chi^{2}=5.829\right.$, $\mathrm{df}=1, \mathrm{p}=0.016)$ that remained after stratification by gender (OR 1.83, 95\% CI 1.12-2.99, p=0.016) (Figure 1).

And Table 2 shows the results of the $\chi^{2}$ test between the DOT and the medication shortages and residuals (316 effective answers). The core period group comprised 91 patients, of which 48 patients had medication shortages or residuals, but 43 did not; the corresponding values for the other group were 225 (total), 90 (yes), and 135 (no). The ratio of medication shortages and residuals was significantly higher in the core period group $\left(X^{2}=4.280, d f=1, p=0.039\right)$. Significance remained after stratification by gender (OR 1.67, 95\% CI 1.022.73, $\mathrm{p}=0.040$ ) (Figure 2).

The results of the logistic regression analysis to identify pre- 
Table 2. Comparing the duration of outpatient treatment and medication shortages or residual medications

\begin{tabular}{|c|c|c|c|c|}
\hline & \multicolumn{3}{|c|}{ Duration of outpatient treatment } & \multirow{2}{*}{$\chi^{2}, \mathrm{df}, \mathrm{p}$} \\
\hline & $1-5$ years & $<1$ year or $\geq 5$ years & Total & \\
\hline Medication shortages $(\mathrm{N}=318)$ & & & & $0.004,1,0.951$ \\
\hline "Yes" & 7 & 17 & 24 & \\
\hline "No" & 84 & 210 & 294 & \\
\hline Total & 91 & 227 & 318 & \\
\hline Residual medications $(\mathrm{N}=316)$ & & & & $5.827,1,0.016$ \\
\hline "Yes" & 47 & 83 & 130 & \\
\hline "No" & 44 & 142 & 186 & \\
\hline Total & 91 & 225 & 316 & \\
\hline Medication shortages or residuals $(\mathrm{N}=316)$ & & & & 1.28. $1,0.039$ \\
\hline "Yes" & 48 & 90 & 138 & \\
\hline "No" & 43 & 135 & 178 & \\
\hline Total & 91 & 225 & 316 & \\
\hline
\end{tabular}

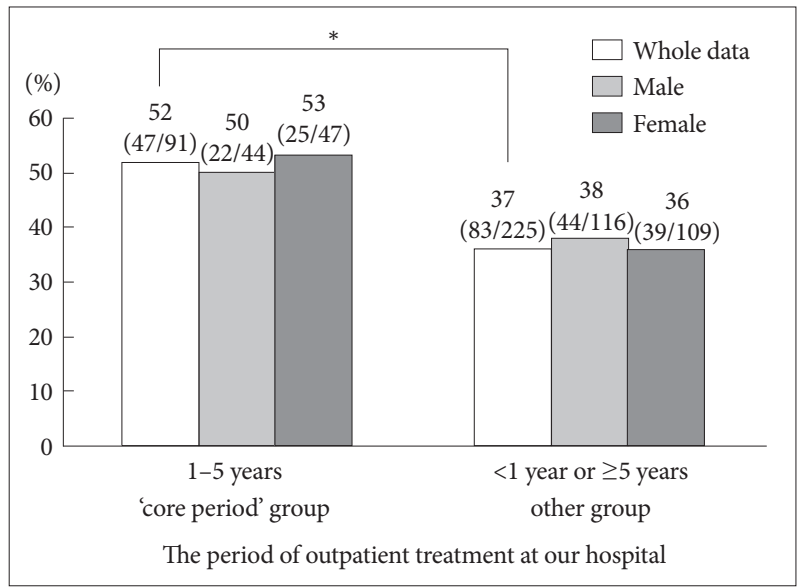

Figure 1. The rate of residual medication. Pearson's $\chi^{2}$ test to determine the association with the period of outpatient treatment to "our" hospital and the ratio of the rest of prescribed drugs. And we analyzed gender as stratification factor in Mantel-Haenszel analysis. OR $1.83,95 \% \mathrm{Cl} 1.12-2.99 .{ }^{*} \mathrm{p}=0.016$.

dictors affecting poor adherence are presented in Table 3. Although none of the independent variables exhibited statistical significance, there tended to be an increased risk of poor adherence among those with a DOT of $1-5$ years (OR 1.602, $95 \% \mathrm{CI}=0.961-2.670, \mathrm{p}=0.071$ ).

\section{DISCUSSION}

We used a cross-sectional, questionnaire-based survey to determine if there was an association between the DOT at our hospital and residual medication among outpatients with schizophrenia. In this survey, since $65 \%$ of all patients with schizophrenia who visited our hospital within research period visited from onset and $76 \%$ of them met classification criteria. Therefore, it might be suggested that "DOT from onset"

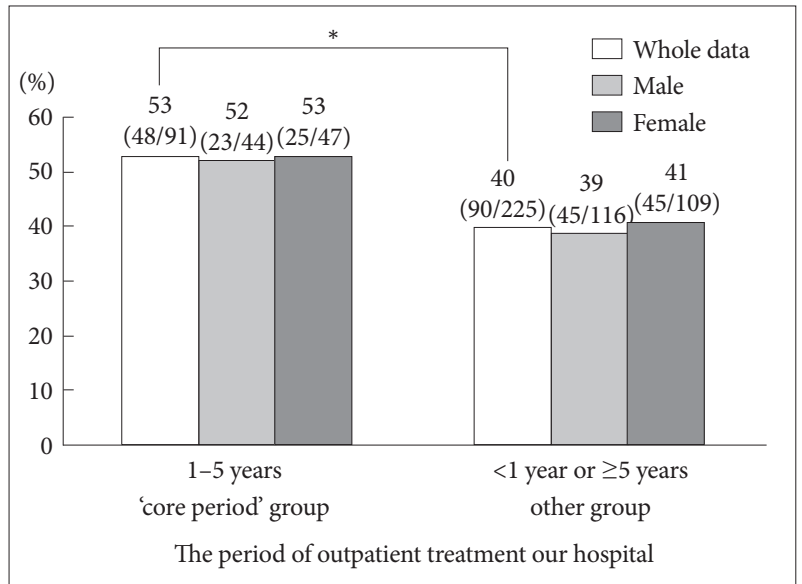

Figure 2. The rate of medication shortaages or residuals. Pearson's $\chi^{2}$ test to determine the association with the period of outpatient treatment to "our" hospital and the ratio of the rest of prescribed drugs. And we analyzed gender as stratification factor in MantelHaenszel analysis. OR 1.67, 95\% Cl 1.02-2.73. ${ }^{*} p=0.040$.

and "DOT at our hospital" were considered to be similar in this survey. There was evidence of an association between outpatients with schizophrenia visiting our hospital during the core period ( $1-5$ years) and not taking medications, as indicated by the rate of residual medications during this time.

Approximately $40 \%$ of patients with schizophrenia are reported to have poor adherence, ${ }^{29}$ which is comparable to our data. Additionally, studies have reported that medication adherence and relapse are correlated, particularly during critical periods $s^{30}$ between one and five years after the onset of schizophrenia. ${ }^{26}$ Many studies have reported a relationship between relapse after clinical response to medication after the first episode of schizophrenia or schizoaffective disorder, but few have considered the relationship between adherence and DOT at a single institute. This may be partially due to different med- 
Table 3. Logistic regression analysis to identify predictors of poor medication adherence

\begin{tabular}{|c|c|c|c|c|c|c|}
\hline & $\mathrm{B}$ & SE & Wald & $\operatorname{Exp}(B)$ & $95 \% \mathrm{CI}$ & $\mathrm{p}$ \\
\hline \multicolumn{7}{|l|}{ Gender } \\
\hline Male & & & & 1.00 & & \\
\hline Female & 0.011 & 0.314 & 0.001 & 1.011 & $0.546-1.870$ & 0.973 \\
\hline \multicolumn{7}{|l|}{ Age } \\
\hline-29 & & & & 1.00 & & \\
\hline $30-39$ & 0.074 & 0.476 & 0.024 & 1.077 & $0.424-2.735$ & 0.877 \\
\hline $40-49$ & -0.449 & 0.477 & 0.887 & 0.638 & $0.250-1.626$ & 0.346 \\
\hline $50-59$ & -0.316 & 0.530 & 0.356 & 0.729 & $0.258-2.059$ & 0.551 \\
\hline $60-$ & -0.479 & 0.498 & 0.926 & 0.619 & $0.233-1.644$ & 0.336 \\
\hline \multicolumn{7}{|l|}{ DOT } \\
\hline$<1$ year or $\geq 5$ years & & & & 1.00 & & \\
\hline $1-5$ years & 0.471 & 0.261 & 3.264 & 1.602 & $0.961-2.670$ & $0.071^{*}$ \\
\hline
\end{tabular}

${ }^{*} \mathrm{p}<0.1$. DOT: duration of outpatient treatment, SE: standard error, CI: confidence interval

ical models operating throughout the world, such as the universalistic, social insurance, and market-oriented models.

Our results revealed a significantly high rate of residual medication in the core period group, which corresponded to the critical period previously reported, suggesting that poor adherence in this period has some relationship with relapse of schizophrenia, regardless of gender. This stresses the importance of treatment early in the course of the disease. Moreover, the critical period may be particularly important because it often represents a period when the patient starts to accept life with schizophrenia and moves from involuntary treatment to self-actualization. While the regression analysis yielded no statistical significance, the data show that there tended to be an increased risk of poor adherence with a DOT of 1-5 years. A larger sample size would improve the statistical power of this data. The data support the hypothesis that medication adherence among schizophrenic patients is reduced after a DOT of $1-5$ years.

Although at least 21 days are normally required for habituation of behavior, ${ }^{31}$ more time may be needed to habituate following a significant event or task. Habit is defined as a learned behavioral response that has become associated with a particular situation, especially one that is frequently repeated. ${ }^{32}$ Assuming that clinical deterioration in schizophrenia is not fixed, it may be that it takes $1-5$ years for patients to habituate to medication that was initiated on an involuntary basis.

Over $82 \%$ of patients with schizophrenia regularly visit hospital at 4-week intervals for outpatient treatment, ${ }^{28}$ and many with unstable conditions visit every 2-4 weeks. The response rate of $87 \%$ to this survey may reflect outpatients with unstable illness. It is essential that we objectively evaluate the DOT significantly related to adherence. Although the duration of untreated psychosis is a useful predictor of outcome, ${ }^{33-35}$ evalu- ator and reporting biases remain important issues. In addition, it can be very difficult to identify the precise time of onset of symptomatic relapse, which is an important social predictor. Differences in evaluating the time of onset of subjective and objective symptoms can be caused by differences in the therapeutic relationship, available support systems, cultural backgrounds and protective factors. ${ }^{36}$

It is important to offer appropriate biological pharmacotherapy. The choice of antipsychotic is recognized to be a central problem in non-adherence and subsequent relapse. We can no longer ignore the fact that second-generation antipsychotics have superior adherence, and that long-acting depot injections offer alternative definitive treatment. ${ }^{17,37}$ Equally, we must remember that these do not solve the fundamental issues with non-adherence.

Psychotherapy is also important for patients with schizophrenia. Indeed, psychoeducation, ${ }^{38}$ social-skill training, ${ }^{39,40}$ cognitive remediation therapy, ${ }^{41}$ and cognitive behavioral group therapy ${ }^{42,43}$ have all proven effective. The distribution and efficacy of these structured programs in Japan is hard to qualify. Despite the presence of 24980 clinical psychologists in Japan in 2013, ${ }^{44}$ the Japanese government does not provide a recognized national qualification and does not allow or fund acute-care psychotherapy. In contrast, there are about 18549 chartered psychologists in the UK in 2013 and 106500 practicing psychologists in the US in $2012 .{ }^{45,46}$ Therefore, staff assignment may be very different from that in the UK and the US.

Social assistance is available for patients in Japan during specific treatment periods. However, this does not specify continual visitation to a specific mental health institution. Thus, when treatment difficulties occur or patients become frustrated, they can readily change where they receive treatment. Coupled with the fact that medical institutions do not share a 
common reporting format, it can be difficult to share patient information concerning disease onset.

Hospitalization and follow-up are ongoing issues with research into relapse rates. Many reports have stated that relapse of schizophrenia requires hospitalization. ${ }^{47}$ However, when patients are free to decide on which institution to attend, there can be a loss in follow-up because it becomes impractical to find the details of other admissions. In countries with a social insurance model, the medical system encourages freedom of choice and personal responsibility. However, in October 2011, private mental health institutions in Japan were chosen 18 times more often than public mental health institutions. ${ }^{48}$ Furthermore, economic costs are sometimes more pressing than the provision of mental healthcare services in many non-specialist medical institutions that offer a greater range of services. Under such situations, it is hard to say whether patient choice should be prioritized. Nevertheless, efforts are needed to integrated medical data in chronic diseases with each medical institution responsible for facilitating outpatient treatment continuation. National guidelines and budgets are urgently needed to resolve these issues.

As a cross-sectional survey, we were only able to discern the correlation between the DOT and medication adherence; it was not possible to determine a causal association.

In addition, in countries in which the social insurance model is adopted, under which patients can change hospital at will, it is difficult to obtain accurate onset data. Therefore, DOT was adopted in the present study as an objective indicator. Although the DOT of the present cases is not an accurate representation, we believe that our data partially indicate the practical DOT. Since we surveyed the patients only using a questionnaire, this represents one of the study limitations.

Furthermore, we did not use a formal letter of consent or obtain background data for the participants. Therefore, we did not compare basic participant information such as premorbid adjustment, age of onset, mode of onset, gender, duration of psychosis, schizophrenia subtype, primary negative symptoms, and extrapyramidal signs (e.g., tardive dyskinesia). ${ }^{49}$ However, there may have been less reporting bias and increased survey recovery rates as a result. Finally, we only included patients that visited one medical institution in this survey, with $13 \%$ of available patients not participating. Thus, important factors related to treatment continuation may have been missed. Considering this selection bias, the generalizability of the survey is limited. A future study should obtain more detailed stratification factors and perform analysis with logistic regression. Although there are various factors associated with poor prognosis, a common one may be related to continued visits to the same mental health institution. A multicenter study may therefore be warranted.
Medication adherence among outpatients with schizophrenia may be related to the DOT at a mental health institution, especially in countries that employ a social insurance model of healthcare. To encourage patients with schizophrenia to continue outpatient treatment over critical periods, it is vital to employ evidence-based management. Our survey suggests that we need to take specific measures to ensure patients have reduced risks of non-adherence during critical periods.

\section{Acknowledgments}

There are no funding sources for this study. And the authors declare no conflict of interest. We thank the nursing staff in outpatient department (Tamayo Danjo, Miki Kohri, Junko Umeno, Kinue Inoue, Yukie Shoji, Shizuko Nakatani, Naoko Kadota, and Yuriko Matsui) of Shin-Abuyama hospital for their efforts in collecting the questionnaires.

\section{REFERENCES}

1. Valenstein M, Copeland LA, Blow FC, McCarthy JF, Zeber JE, Gillon L, et al. Pharmacy data identify poorly adherent patients with schizophrenia at increased risk for admission. Med Care 2002;40:630-639.

2. Weiden PJ, Kozma C, Grogg A, Locklear J. Partial compliance and risk of rehospitalization among California Medicaid patients with schizophrenia. Psychiatr Serv 2004;55:886-891.

3. Ascher-Svanum H, Faries DE, Zhu B, Ernst FR, Swartz MS, Swanson JW. Medication adherence and long-term functional outcomes in the treatment of schizophrenia in usual care. J Clin Psychiatry 2006;67: 453-460.

4. Perkins DO. Adherence to antipsychotic medications. J Clin Psychiatry 1999;60(Suppl 21):25-30.

5. Fleischhacker WW, Oehl MA, Hummer M. Factors influencing compliance in schizophrenia patients. J Clin Psychiatry 2003;64(Suppl 16): 10-13.

6. Byerly M, Fisher R, Whatley K, Holland R, Varghese F, Carmody T, et al. A comparison of electronic monitoring vs. clinician rating of antipsychotic adherence in outpatients with schizophrenia. Psychiatry Res 2005;133:129-133.

7. Acosta FJ, Ramallo-Farina Y, Bosch E, Mayans T, Rodriguez CJ, Caravaca A. Antipsychotic treatment dosing profile in patients with schizophrenia evaluated with electronic monitoring $\left(\right.$ MEMS $\left.^{\circledR}\right)$. Schizophr Res 2013;146:196-200.

8. Brain C, Sameby B, Allerby K, Lindstrom E, Eberhard J, Burns T, et al. Twelve months of electronic monitoring $\left(\right.$ MEMS $\left.^{\circledR}\right)$ in the Swedish COAST-study: a comparison of methods for the measurement of adherence in schizophrenia. Eur Neuropsychopharmacol 2014;24:215222 .

9. Velligan DI, Lam YW, Glahn DC, Barrett JA, Maples NJ, Ereshefsky L, et al. Defining and assessing adherence to oral antipsychotics: a review of the literature. Schizophr Bull 2006;32:724-742.

10. Gutierrez-Casares JR, Canas F, Rodriguez-Morales A, Hidalgo-Borrajo $\mathrm{R}$, Alonso-Escolano D. Adherence to treatment and therapeutic strategies in schizophrenic patients: the ADHERE study. CNS Spectr 2010; 15:327-337.

11. Lehman AF, Lieberman JA, Dixon LB, McGlashan TH, Miller AL, Perkins DO, et al. Practice guideline for the treatment of patients with schizophrenia, second edition. Am J Psychiatry 2004;161(2 Suppl): $1-56$.

12. Gorwood P. Meeting everyday challenges: antipsychotic therapy in the real world. Eur Neuropsychopharmacol 2006;16(Suppl 3):S156-S162.

13. Leucht S, Corves C, Arbter D, Engel RR, Li C, Davis JM. Second-generation versus first-generation antipsychotic drugs for schizophrenia: a meta-analysis. Lancet 2009;373:31-41. 
14. Hartling L, Abou-Setta AM, Dursun S, Mousavi SS, Pasichnyk D, Newton AS. Antipsychotics in adults with schizophrenia: comparative effectiveness of first-generation versus second-generation medications: a systematic review and meta-analysis. Ann Intern Med 2012;157:498-511.

15. Leucht S, Cipriani A, Spineli L, Mavridis D, Orey D, Richter F, et al. Comparative efficacy and tolerability of 15 antipsychotic drugs in schizophrenia: a multiple-treatments meta-analysis. Lancet 2013;382: 951-962.

16. Panish J, Karve S, Candrilli SD, Dirani R. Association between adherence to and persistence with atypical antipsychotics and psychiatric relapse among US Medicaid-enrolled patients with schizophrenia. J Pharm Health Serv Res 2013;4:29-39.

17. Olivares JM, Rodriguez-Morales A, Diels J, Povey M, Jacobs A, Zhao Z, et al. Long-term outcomes in patients with schizophrenia treated with risperidone long-acting injection or oral antipsychotics in Spain: results from the electronic Schizophrenia Treatment Adherence Registry (eSTAR). Eur Psychiatry 2009;24:287-296.

18. Macfadden W, Ma YW, Thomas Haskins J, Bossie CA, Alphs L. A prospective study comparing the long-term effectiveness of injectable risperidone long-acting therapy and oral aripiprazole in patients with schizophrenia. Psychiatry (Edgmont) 2010;7:23-31.

19. Marco CA, Vaughan J. Emergency management of agitation in schizophrenia. Am J Emerg Med 2005;23:767-776.

20. Keith SJ, Kane JM. Partial compliance and patient consequences in schizophrenia: our patients can do better. J Clin Psychiatry 2003;64: 1308-1315.

21. Kukla M, Salyers MP, Lysaker PH. Levels of patient activation among adults with schizophrenia: associations with hope, symptoms, medication adherence, and recovery attitudes. J Nerv Ment Dis 2013;201:339344.

22. Priebe S, Yeeles K, Bremner S, Lauber C, Eldridge S, Ashby D, et al. Effectiveness of financial incentives to improve adherence to maintenance treatment with antipsychotics: cluster randomised controlled trial. BMJ 2013;347:f5847.

23. Thorndike EL, University C. The law of effect. Am J Psychol 1927;39: 212-222.

24. de Haan L, van Amelsvoort T, Dingemans P, Linszen D. Risk factors for medication non-adherence in patients with first episode schizophrenia and related disorders; a prospective five year follow-up. Pharmacopsychiatry 2007;40:264-268.

25. Tiihonen J, Lonnqvist J, Wahlbeck K, Klaukka T, Niskanen L, Tanskanen A, et al. 11-year follow-up of mortality in patients with schizophrenia: a population-based cohort study (FIN11 study). Lancet 2009; 374:620-627.

26. Robinson D, Woerner MG, Alvir JM, Bilder R, Goldman R, Geisler S, et al. Predictors of relapse following response from a first episode of schizophrenia or schizoaffective disorder. Arch Gen Psychiatry 1999; 56:241-247.

27. World Health Organization. International Statistical Classification of Diseases and Related Health Problems 10th Revision. Geneva: World Health Organization; 1992.

28. Ikebuchi E, National Federation of Mental Health and Welfare Party in Japan. Questionnaire about Life and the Treatment of the Person Mentally Challenged. Tokyo: National Federation of Mental Health and Welfare Party in Japan; 2011.

29. Valenstein M, Ganoczy D, McCarthy JF, Myra Kim H, Lee TA, Blow FC. Antipsychotic adherence over time among patients receiving treatment for schizophrenia: a retrospective review. J Clin Psychiatry 2006;67:
1542-1550.

30. Birchwood M, Todd P, Jackson C. Early intervention in psychosis. The critical period hypothesis. Br J Psychiatry Suppl 1998;172:53-59.

31. Jeremy Dean OP. Making Habits, Breaking Habits: How to Make Changes that Stick. Boston: Da capo Press; 2013.

32. Cobuild C. Collins Cobuild Advanced Dictionary of English 7th edition. Boston: Heinle \& Heinle Pub; 2012.

33. Crow TJ, MacMillan JF, Johnson AL, Johnstone EC. A randomised controlled trial of prophylactic neuroleptic treatment. Br J Psychiatry 1986;148:120-127.

34. Johnstone EC, Macmillan JF, Frith CD, Benn DK, Crow TJ. Further investigation of the predictors of outcome following first schizophrenic episodes. Br J Psychiatry 1990;157:182-189.

35. Drake RJ, Haley CJ, Akhtar S, Lewis SW. Causes and consequences of duration of untreated psychosis in schizophrenia. Br J Psychiatry 2000; 177:511-515.

36. Lamberti JS. Seven keys to relapse prevention in schizophrenia. J Psychiatr Pract 2001;7:253-259.

37. Hogarty GE, Schooler NR, Ulrich R, Mussare F, Ferro P, Herron E. Fluphenazine and social therapy in the aftercare of schizophrenic patients. Relapse analyses of a two-year controlled study of fluphenazine decanoate and fluphenazine hydrochloride. Arch Gen Psychiatry 1979;36: 1283-1294.

38. Pekkala E, Merinder L. Psychoeducation for schizophrenia. Cochrane Database Syst Rev 2000:Cd002831.

39. Benton MK, Schroeder HE. Social skills training with schizophrenics: a meta-analytic evaluation. J Consult Clin Psychol 1990;58:741-747.

40. Wallace CJ, Liberman RP, MacKain SJ, Blackwell G, Eckman TA. Effectiveness and replicability of modules for teaching social and instrumental skills to the severely mentally ill. Am J Psychiatry 1992;149: 654-658.

41. McGurk SR, Mueser KT, Feldman K, Wolfe R, Pascaris A. Cognitive training for supported employment: 2-3 year outcomes of a randomized controlled trial. Am J Psychiatry 2007;164:437-441.

42. Bechdolf A, Kohn D, Knost B, Pukrop R, Klosterkotter J. A randomized comparison of group cognitive-behavioural therapy and group psychoeducation in acute patients with schizophrenia: outcome at 24 months. Acta Psychiatr Scand 2005;112:173-179.

43. Penn DL, Meyer PS, Evans E, Wirth RJ, Cai K, Burchinal M. A randomized controlled trial of group cognitive-behavioral therapy vs. enhanced supportive therapy for auditory hallucinations. Schizophr Res 2009;109:52-59.

44. Japanese Society of Certified Clinical Psychologists. Available at: http:// www.jsccp.jp/person/about.php. Accessed October 5, 2015.

45. The British Psychological Society. Available at: http://www.bps.org.uk/ contact-details/contact-details. Accessed March 11, 2015.

46. American Psychological Association. Available at: http://www.apa.org/ support/. Accessed October 5, 2015.

47. Olivares JM, Sermon J, Hemels M, Schreiner A. Definitions and drivers of relapse in patients with schizophrenia: a systematic literature review. Ann Gen Psychiatry 2013;12:32.

48. Ministry of Health, Labour and Welfare. Overview of Medical Facilities (Static, Dynamic) Research and Hospital Report. Tokyo: Ministry of Health, Labour and Welfare; 2012.

49. Lieberman JA, Koreen AR, Chakos M, Sheitman B, Woerner M, Alvir $\mathrm{JM}$, et al. Factors influencing treatment response and outcome of firstepisode schizophrenia: implications for understanding the pathophysiology of schizophrenia. J Clin Psychiatry 1996;57(Suppl 9):5-9. 